\title{
Myocardial Bridge in a Patient with Sickle Cell Anemia
}

\author{
Marco Aurélio de Seixas, Carlos Alberto Franchin Jr, Carlos Eduardo Suaide Silva, \\ Samira Morhy Borges Leal, Juarez Ortiz
}

\author{
São Paulo, SP - Brazil
}

Sickle cell anemia (SCA) is a hereditary condition that occurs almost exclusively in blacks. It is characterized hematologically by the presence of sickle erythrocytes. This sickling phenomenon results from low oxygen tensions. A number of vaso-occlusive events may occur, involving the microcirculation or even large arteries. Arterial occlusion results from the interaction of remuved abnormal erythrocytes with the vascular wall. Not rarely, cases of splenic infarct and microscopic hematuria are found ${ }^{1}$. Pulmonary hypertension is frequently attributed to SCA. An association with lethal and nonlethal cardiovascular events has also been reported ${ }^{2}$. In spite of the potential ischemic impairment of many tissues, the literature regarding SCA's association with coronary disease is scarce.

Our objective is to report the case of a young woman with chest pain who had an association of SCA with myocardial bridge (MB).

\section{Case report}

The patient, a 34-year-old mulatto female with a previous history of $\mathrm{SCD}$, reported the onset of a burning sensation in her left hemithorax beginning two months before presentation for treatment. The symptoms were triggered by physical exertion and irradiated to the cervical region and the left upper limb. She also had palpitations and syncope.

On physical examination the patient was in good health, hydrated, eupneic, acyanotic, and her mucous membranes were not pale. The examination of the heart, lung and abdomen revealed no abnormalities. Her blood pressure was $120 / 80 \mathrm{~mm} \mathrm{Hg}$ and her heart rate was $80 \mathrm{bpm}$.

Hematological tests revealed the following findings: red cells, 3.79 million $/ \mathrm{mm}^{3}$; hemoglobin, $12.2 \mathrm{~g} \%$; hematocrit, $39 \%$; reticulocyte count, $3.1 \%$; she had a normal white blood cell count and a positive sickling test. Hemoglobin electrophoresis showed $55.4 \%$ of $\mathrm{HbS}$ and $44.1 \%$ of $\mathrm{HbC}$.

The electrocardiogram at rest, the chest X-ray, and the transthoracic Doppler echocardiogram showed no abnor-

Centro de Cardiologia Não Invasiva - São Paulo

Mailing address: Marco Aurélio de Seixas - Centro de Cardiologia Não Invasiva - Rua Cubatão, 726 - 04013-002 - São Paulo, SP - Brazil malities. The treadmill test, performed according to the Memorial Hospital protocol, which uses three modified simultaneous leads, showed, at peak exercise, electrocardiographic abnormalities consistent with an ischemic myocardial response to exercise (maximum ST-segment downslope of $2.5 \mathrm{~mm}$ in lead V5, and a flattened morphology of the STsegment) patient remained asymptomatic. An echocardiogram with pharmacological stress was performed, with the infusion of dobutamine $(10 \mathrm{mg} / \mathrm{kg} / \mathrm{min}$, with progressive increments of $10 \mathrm{mg} / \mathrm{kg} / \mathrm{min}$ each 3 minutes until the maximum dose of $40 \mathrm{mg} / \mathrm{kg} / \mathrm{min}$ was reached), followed by atropine $(0.75 \mathrm{mg}$ in 3 doses of $0.25 \mathrm{mg})$ in order to potentiate the test. At this moment, the images obtained were suggestive of myocardial ischemia (slight hypocinesia in the medium and apical portion of the anterior interventricular septum) (fig. 1). Myocardial scintigraphy with SESTAMIBI combined with a treadmill test showed that the perfusion and global function of the left ventricle (LV) were within the normal range, despite of the presence of electrocardiographic abnormalities (maximum ST-segment downslope of $3.0 \mathrm{~mm}$ in lead V5) (fig. 2).

Due to the abnormalities that were found, the patient underwent coronary arteriography, which did not reveal obstructive lesions. However, the anterior descending artery showed intramyocardial trajectory in its medium third (fig. 3).

The patient was treated with pentoxifylline, folic acid and vitamin $C$, with clinical improvement.

\section{Discussion}

SCA is a common disease in blacks with an estimated incidence of $0.3 \%$ to $1 \%$ of North Americans with the homozygous state (sickle cell anemia) and of $8 \%$ to $13 \%$ with the heterozygous state (sickle cell trait). In the city of São Paulo, $0.1 \%$ of the newborns show the homozygous state of sickle cell disease. In the state of Bahia, SCA is the most common genetic condition ${ }^{3}$.

This condition has different prognoses, depending on the genetic presentation. The poorest prognosis is found in those persons with the homozygous state ${ }^{4}$. The heterozygous state is associated with a long survival and less severe complications. Clinical manifestations are basically the 


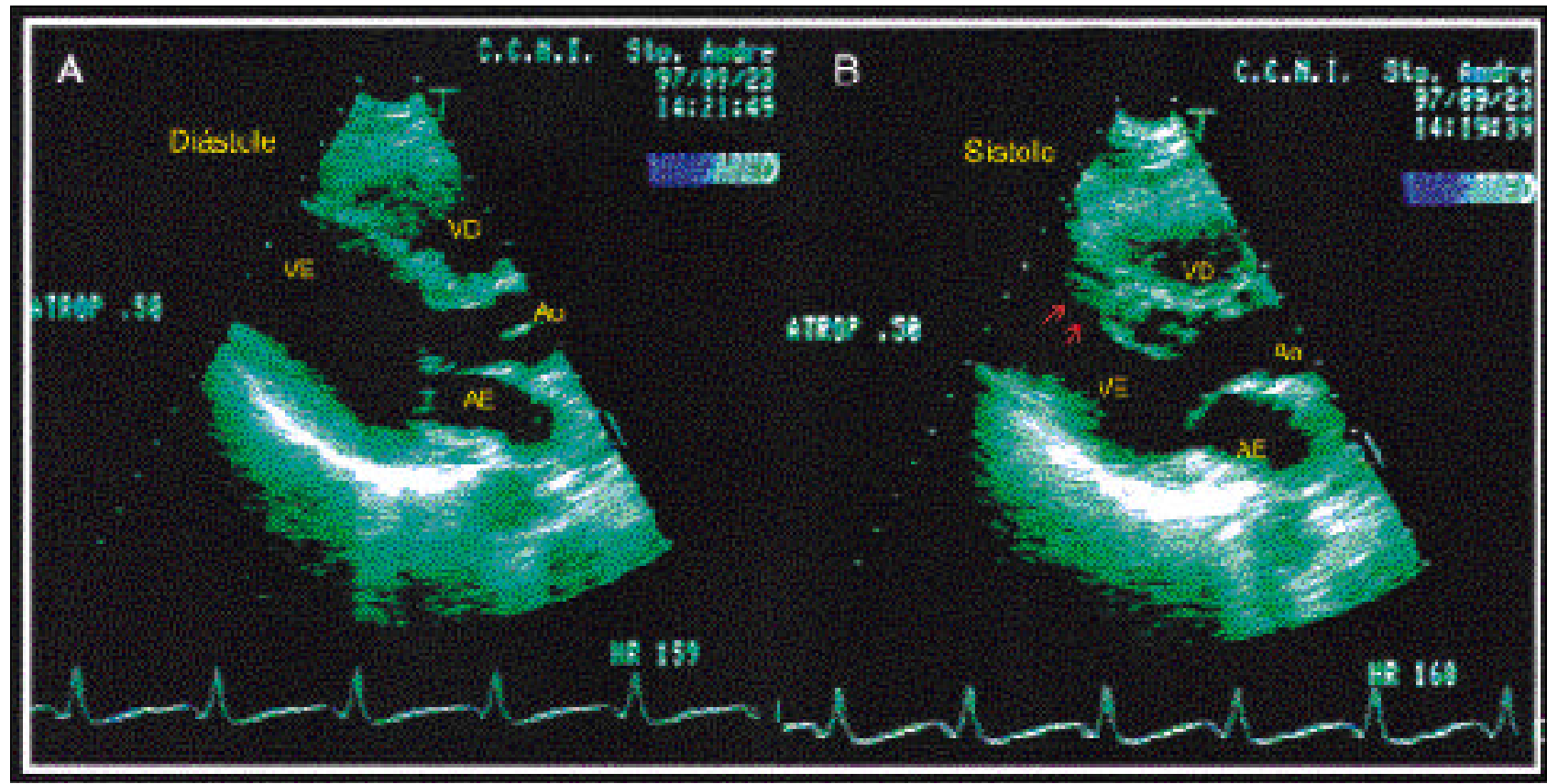

Fig. 1 - Echocardiography with pharmacological stress showing an area of reduced contractility in the middle region of the anterior septum (arrows).

result of anemia and tissue ischemia. The former is usually severe, but varies according to each individual.

The sickle erythrocytes contain an abnormal hemoglobin (called S hemoglobin [HbS]). When exposed to low oxygen tensions, this hemoglobin precipitates forming long crystals. These crystals stretch the cells, giving them the appearance of a sickle. Individuals with more than $40 \%$ of $\mathrm{HbS}$ show a great incidence of sickling ${ }^{4}$. During sickling crises, blood flow through the tissues is impaired, resulting in an additional decrease in the oxygen concentration.

$\mathrm{MB}$ is an uncommon occurrence. It is found in approximately $0.5 \%-12 \%$ of coronary angiographies, and most cases show the involvement of the anterior descending artery ${ }^{5}$. The clinical significance of this condition is controversial. Although most patients show a benign outcome, cases of disabling angina, myocardial infarction (MI), arrhythmias and sudden death have been reported ${ }^{6}$. The degree of systolic compression caused by the MB and the presence of other diseases may account for this poor prognosis.

Many studies have investigated the presence, the extent and the form of cardiovascular involvement in SCA, including the presence of electrocardiographic abnormalities, variant angina and MI. Sudden death has often been documented ${ }^{7}$. Reports of the association of exertion-induced myocardial ischemia, as evidenced in this case, and potentially hypoxemic conditions (acidosis, dehydration, severe infections, hyperthermia, organ failure, among others) with SCA are not rare.

The pathophysiological mechanisms implicated in sudden death are unclear. An interference with the endothelium-dependent vasodilation process through inhibition of the EDRF (endothelium-derived relaxing factor) is sugges- $\operatorname{ted}^{8}$. The final pathway leading to these microvascular abnormalities would be lethal electric instability.

It is generally agreed that the risk of sudden death increases 25-30 times with strenuous physical exertion ${ }^{9}$. On the other hand, the reasons why most patients with sickle cell trait exercise vigorously without any consequences are unclear. It is assumed that there is a second risk factor for sudden death ${ }^{10}$. Until now, these factors would be vigorous physical exercise, dehydration, hyperthermia and high altitudes. All these elements can act together, ultimately leading to death.

Chest pain was the main reason for this patient seeking medical assistance. It is a frequent and mostly disabling symptom in these individuals. It is not difficult for us to consider this symptom a result of the ischemic cascade caused by low oxygen tensions in the cardiac muscle. Lesions of the pulmonary vasculature and concurrent pulmonary hypertension are also implicated as causes of pain and dyspnea (although with some controversy) ${ }^{11}$.

The presence of pain is associated with different prognostic implications. A recent study made an analysis of the survival curves in individuals $\geq 20$ years of age with SCA, taking into account the frequency of pain episodes. An increased mortality was observed in those who had 3 or more episodes per year. Thus, this high prevalence of pain would be a strong indicator of sudden death in this group of young adults. These results were not found in patients under 20 years of age ${ }^{12}$.

Although this patient showed no abnormalities in the echocardiogram at rest, cardiovascular abnormalities are consistently reported in the literature ${ }^{13}$. An important correlation with pulmonary hypertension, enlargement of the left 


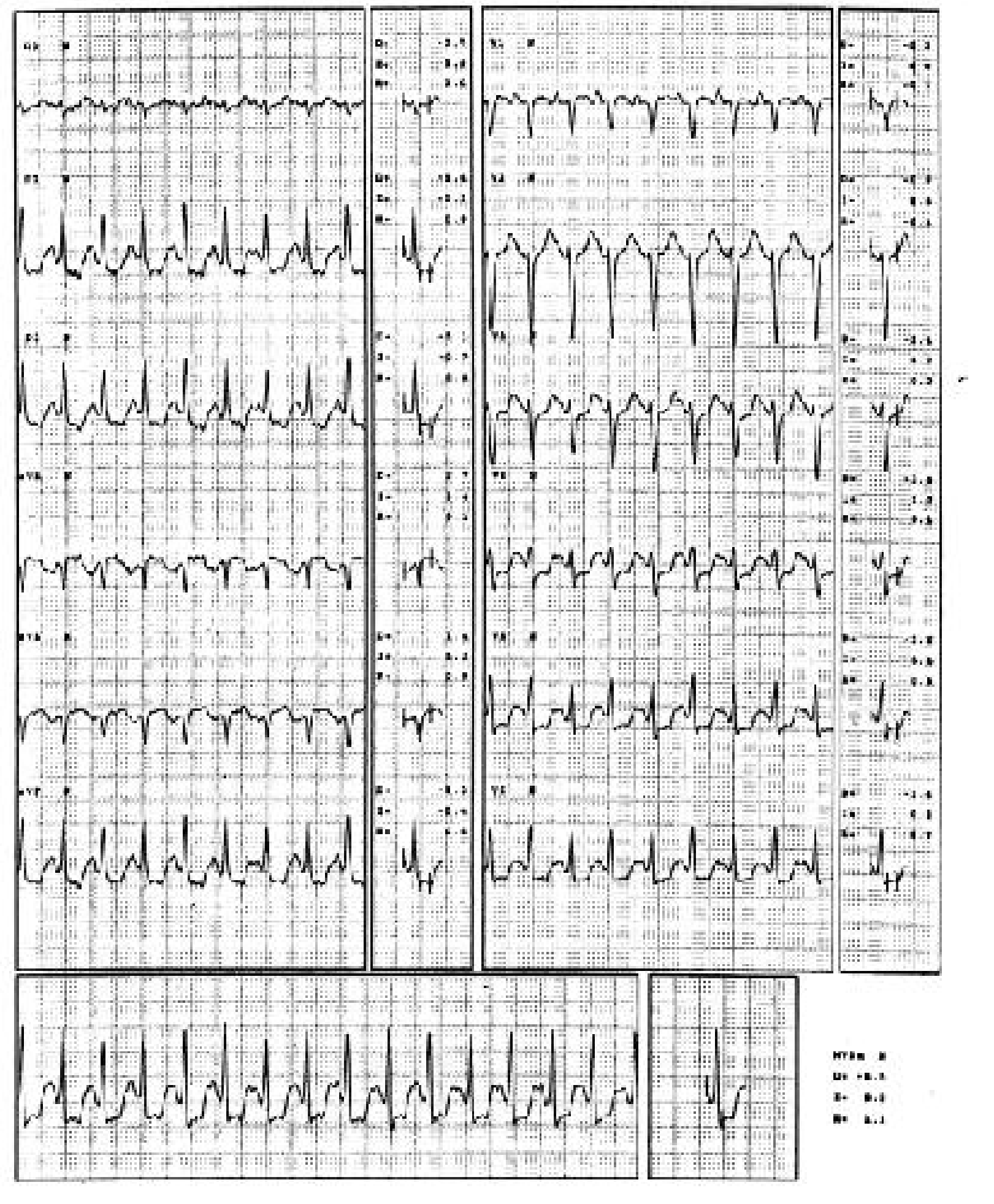

Fig. 2 - Electrocardiogram during exertion. Note the ischemic abnormalities in the classical leads and in lead V5.

chambers and LV mass indexes are also encountered. In the absence of convincing evidence of $\mathrm{LV}$ systolic dysfunction, abnormalities of the diastolic performance have been implicated as a surrogate explanation for symptoms such as dyspnea and exercise intolerance ${ }^{14}$.
The use of stress echocardiography with dobutamine in the evaluation of patients with SCA is still being tested. Therefore, we cannot securely establish concepts on the accuracy of this method. Tio et al ${ }^{15}$, using pharmacological stress combined with positron-emission tomography, 


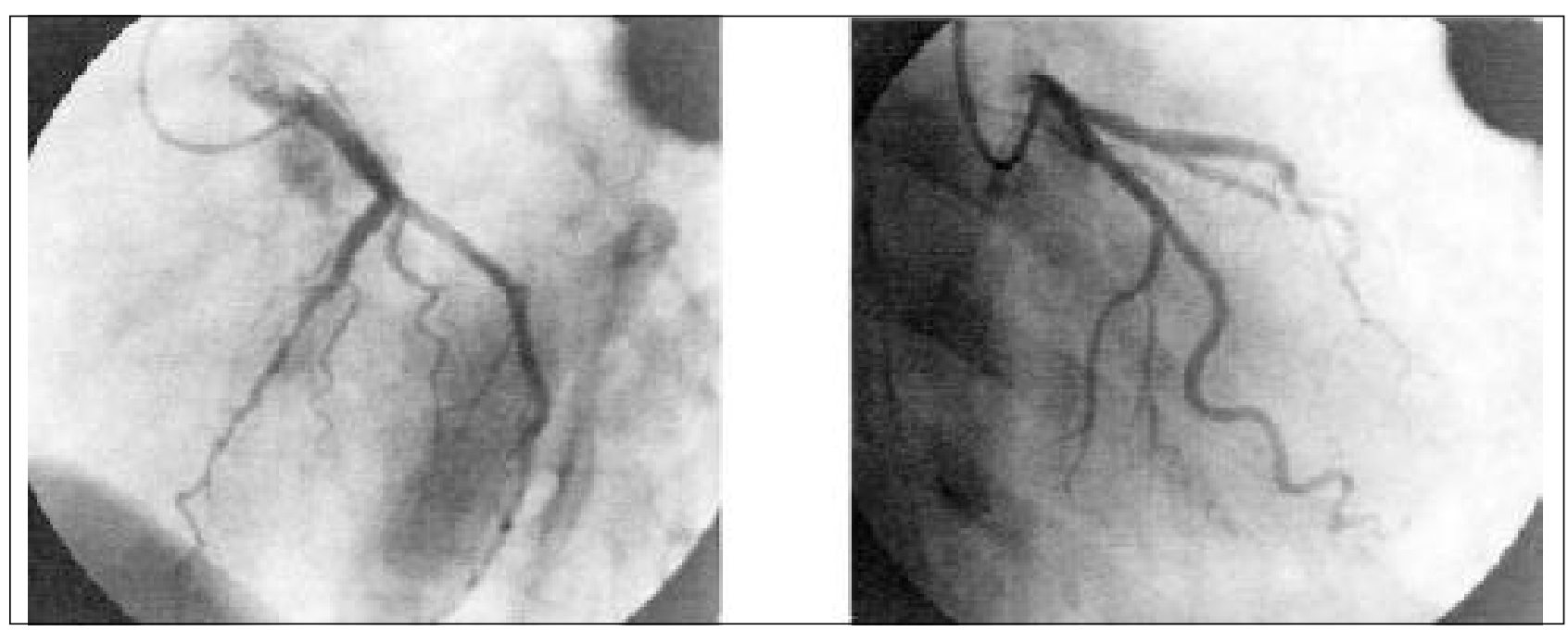

Fig. 3 - Coronary angiography. A) left coronary artery in RAO and LAO, respectively; B) Anterior descending and circumflex arteries without significant atheromatous lesions. Anterior descending artery with an intramyocardial trajectory in its middle third (arrow).

showed myocardial ischemia in a 46-year-old patient with MB who survived a heart attack.

Stress testing in patients with SCA for the evaluation of chest pain often reveals electrocardiographic signs of myocardial ischemia. It is also known that patients with MB often show signs of myocardial ischemia triggered by exertion. These are situations classically labeled as falsepositive in the treadmill test. Myocardial perfusion scintigraphy is very useful in these cases. It is a highly sensitive (80\% to $90 \%$ ) and highly specific (85\% to $90 \%$ ) test ${ }^{16}$. However, it shows conflicting results when the perfusion is normal ${ }^{17,18}$. Other patients demonstrate transient perfusional defects ${ }^{19}$.

In our opinion, these differences are due to the methodology employed (physical or pharmacological stress), to the association with other diseases potentially causing ischemia, and to the different degrees of systolic compression caused by $\mathrm{MB}$ (there is an increase in systolic compres- sion when vasodilator or inotropic drugs are used). Thus, the clinical implications of a positive test must be considered with caution.

The patient presented here had a positive treadmill test and a negative myocardial scintigraphy. Although believing that the presence of $\mathrm{MB}$ contributed more to the genesis of the signs and symptoms of ischemia, we cannot precisely define what was the most important factor. Furthermore, we must consider the association of other associated factors causing the reported signs and symptoms.

In the present report, the casual finding of MB has made us emphasize the importance of a careful investigation and of the differential diagnosis of chest pain in young women. Furthermore, it is critical to promptly diagnose the sickle cell anemia to minimize its consequences, as the morbidity and mortality of this disease are well recognized. It seems to us that these individuals with SCD must have their risk factors reduced, as much as possible.

\section{References}

1. Kerle KK, Nishimura KD. Exertional collapse and sudden death associated with sickle cell trait. Am Fam Physician 1996; 54: 237-40.

2. Evans P. Sudden exertional death and sickle cell trait. Am Fam Physician 1996; 55: 784.

3. Gonçalves MS, Nechtman JF, Figueiredo MS, et al. Sickle cell disease in a Brazilian population from São Paulo: a study of the beta-haplotypes. Hum Hered 1994; 44: 322-7.

4. James TN, Riddick L, Massing GK. Sickle cell and sudden death: morphologic abnormalities of the cardiac conduction system. J Lab Clin Med 1994; 124: 507-20.

5. Kramer JR, Kitazume H, Proudfit WL, et al. Clinical significante of isolated coronary bridges: benign and frequent condition involving the left anterior descending artery. Am Heart J 1982; 10: 283-8.

6. Rosencrance G, Deer TR, Lee KC, et al. Coronary artery muscle bridging causing class III angina in a patient with no coronary atherosclerosis. W Virg Med J 1995; 91: 196-7.

7. Sateriale M, Hart P. Unexpected death in a black military recruit with sickle cell trait: case report. Mil Med 1985; 150: 602-5.
8. Mosseri M, Barlett-Pandie NA, Wenck K, et al. Inhibition of endotheliumdependent vasorelaxation by sickle erythrocytes. Am Heart J 1993; 26: 338-45.

9. Brewer GJ. Risks in sickle cell trait. J Lab Clin Med 1993; 122: 354-5.

10. Nuss R, Loehr JP, Daberkow E, et al. Cardiopulmonary function in men with sickle cell trait who reside at moderately high altitude. J Lab Clin Med 1993; 122: 382-7.

11. Haupt HM, Moore GW, Bauer TW, et al. The lung in sickle cell disease. Chest 1982; 81:332-7.

12. Platt OS, Thorington BD, Brambilla DJ, et al. Pain in sickle cell disease. N Engl J Med 1991; 325: 11-6.

13. Simmons BE, Santhanam Y, Castaner A, et al. Two dimensional echo and doppler ultrasonografic findings in the hearts of adult patients with sickle cell anemia. Arch Intern Med 1998; 148: 1526-8.

14. Lewis JF, Maron BJ, Castro O, et al. Left ventricular diastolic filling abnormalities identified by doppler echocardiography in asymptomatic patients with sickle cell anemia. J Am Coll Cardiol 1991; 17: 1473-8.

15. Tio RA, Van Gelder IC, Boonstra PW, et al. Myocardial bridging in a survivor of 
sudden cardiac near-death: role of intracoronary doppler flow measurements and angiography during dobutamine stress in the clinical evaluation. Heart 1997; 77: $280-2$.

16. Iskandrian AS, Hakki AH. Thallium-201 myocardial scintigraphy. Am J Cardiol 1984; 109: 113-23.

17. Greenspan M, Iskandrian AS, Catherwood E, et al. Myocardial bridging of the left anterior descending artery: evaluation using exercise thallium-201 myocardial scintigraphy. Cathet Cardiovasc Diagn 1980; 6: 173-80.
18. Rivitz MS, Yasuda T. Predictive value of dypiridamole thallium imaging in a patient with myocardial bridging but without fixed obstructive coronary disease. J Nucl Med 1992; 33: 1905-13.

19. Bennett JM, Blomerus P. Thallium-201 scintigraphy perfusion defect with dipyridamole in a patient with a myocardial bridge. Clin Cardiol 1988; 11: 268-70.

20. Ribeiro Jorge PA, Abdalla LA, Rocha J, et al. Associação entre ponte miocárdica, prolapso da valva mitral e hipertrofia miocárdica. Arq Bras Cardiol 1986; 47 : 259-62. 